\title{
Applying constrained virtual environments to serious games for heritage
}

\author{
Laurence Hanes ${ }^{1}$, Robert Stone ${ }^{2}$ \\ University of Birmingham \\ \{Lxh519, R.J.Stone\}@bham.ac.uk
}

\section{Abstract}

Virtual environments are an important aspect of serious games for heritage. However, navigable three-dimensional (3D) environments can be costly and resource-intensive to create and for users to run. In this paper, we propose an alternative approach using "constrained virtual environments", which present an environment through a series of reduced fidelity two-dimensional (2D) scenes without exhaustive detail. We describe the development of a constrained virtual environment to replicate a $3 D$ environment from a serious game concerning ancient Mesopotamian history. An exploratory experiment discovered that participants experienced a similar sense of presence in the constrained environment to that of the $3 D$ environment and rated the two games to be of similar quality. Participants were equally likely to pursue further information on the subject matter afterwards and collected more information tokens from within the constrained environment. A subsequent interview with a museum expert explored opportunities for such games to be implemented in museum displays, and based on the experiences and issues encountered, a preliminary set of guidelines was compiled for implementing future constrained virtual environments within serious games for heritage.

Keywords: Serious games, Cultural heritage, 3D virtual environments, Constrained virtual environments, Presence;

\section{Introduction}

\subsection{Serious Games and Virtual Environments for Heritage}

Serious games have attracted significant academic interest, in terms of their design [1]-[3], implementation [4], evaluation [5]-[10], and even from a business perspective [11]. The focus of this paper is on serious games for heritage ( $\mathrm{SGsH}$ ) [12], [13], of which many examples can be found throughout the literature, for both design [14]-[18] and evaluation [19], [20]. Many of these serious games aim to recreate cultural or historical settings of interest to be experienced by the player, whether it be a faraway cultural locale [15], [21], or a historical period or event now long past [22]-[25]. The prospect of being able to see and understand the past through our ancestors' eyes is an undeniably attractive one and likely draws many users to such learning games. Indeed, when Castaneda et al. [26] surveyed a group of adolescents, $44 \%$ said they wanted to use virtual reality to experience historical events or places and $78 \%$ believed that it has the power to take you to another time or place.

These SGsH typically utilise navigable virtual environments to represent culturalhistorical places, and past work has focused on analysing their learning potential [27], [28]. Participants may navigate from a first- or third-person perspective, or by controlling an avatar within the environment, and may interact with artefacts and learning activities 
situated in their natural context. They may also be free to experiment and construct their own learning and meaning from the objects around them.

One noticeable trend within the serious games and reviews so far mentioned is the focus on $3 \mathrm{D}$ technology, environments, and graphics, typically utilising textured polygonal assets. Indeed, in their review of serious games for heritage, Anderson et al. [12] state that "the state-of-the-art in serious game technology is identical to the state-of-the-art in entertainment games technology", even dedicating the second half of the paper to describing 3D graphics techniques. Furthermore, Christopoulou \& Xinogalos [29] found that, of the different game engines used in serious games, Unity and Unreal Engine 4 were the most common, both of which enable the generation of high-fidelity, photorealistic 3D games. However, there are many challenges associated with the use of such 3D graphics technology, including the acquisition and preservation of accurate 3D models [30], the presentation of difficult information such as violence or uncertainty within the source material [31], and the cost for both the user, who requires modern computing hardware to run the applications, and the developer who must design and create the environments. It is widely acknowledged that modern state-of-the-art video games can be extremely expensive to make, and the design, artwork, modelling, texturing, animation, and testing of elaborate 3D environments are just some of the factors that contribute to this. This may be a significant challenge for cultural institutions such as museums, where project budgets cannot accommodate such costs. There is also a trend to design SGsH with more basic visuals and mechanics to accommodate a smaller budget. However, such games do not typically focus on the player's sense of place in a recreated historical environment [13], [32].

\subsection{Discover Babylon and Constrained Virtual Environments}

This paper is part of a project focused on the design of SGsH for ancient Mesopotamian history, a part of the cradle of civilisation that gave rise to written language. One example of a serious game in this field is Discover Babylon [33], a 3D adventure game developed through a partnership of the Federation of American Scientists, the Walters Art Museum of Baltimore, and the Cuneiform Digital Library Initiative of the University of California, Los Angeles, released around 2006 [34]. The target audience of the game was children up to 14 years, and its objectives were to increase players' awareness and appreciation of the significance of Mesopotamia within world history, through a fun and engaging game that delivered an experience comparable with commercial video games [34]. However, the project suffered issues with funding and the game was not finished, instead being migrated to a cooperative learning environment on the Second Life platform [35]. Discover Babylon illustrates the challenges that can be encountered by serious game developers with the ambitious goal of creating educational games comparable with commercial games, but without an equivalent budget. Although the game is now over 10 years old, the situation has arguably become more difficult as the state-of-the-art in 3D technology has advanced.

What then should developers of serious games do in the face of this challenge? The authors of Discover Babylon suggest that the solution is to locate greater sources of funding [34], but we suggest that an alternative approach should be found. We take inspiration from the 'indie games' sector of the commercial video games industry, in which small teams with modest budgets can compete with state-of-the-art, high-budget video games through the innovative use of experimental game mechanics and visual styles [36]. These games often utilise 2D graphics, typically utilising textures or 2D vectors, which require less resources to produce than $3 \mathrm{D}$ environments but are still appealing to audiences.

We identify "constrained virtual environments" as a potential approach, developed by Turner et al. [37]. These consist of a set of scenes, each representing a view of the environment. Each scene is made from layers of $2 \mathrm{D}$ images and, as the user moves the cursor across the screen, the layers move with a parallax effect to create the sense of a 3D scene with depth. The authors argue that such a constrained environment could achieve a comparable sense of place as an equivalent 3D environment, while being realisable with 
fewer resources. While they report positive experimental results, the authors admit that they have not yet compared a constrained environment directly against an equivalent 3D environment.

\subsection{Formulation of the Paper}

The research question of this paper is, therefore, whether serious games for heritage implemented with constrained virtual environments can be as effective as those utilising $3 \mathrm{D}$ environments, in terms of the player's perception of the historical place depicted in the game, the player's enjoyment and perceived quality of the game, and the player's interest in the subject matter after playing, while not compromising the accuracy or authenticity of the subject matter. This paper will detail the development of a constrained virtual environment to recreate one of the levels from Discover Babylon, changing the mode of presentation of the environment but leaving the game mechanics as close to the original as possible, and efforts to compare the two environments experimentally.

In Part 2 we will give an overview of the related work, including the background on virtual environments for learning in heritage, the theory behind constrained environments, and a review of presence, place, and related concepts, to inform exactly how a player's perception of an historical place should be measured. In Part 3 we describe the development of the constrained environment and, in Part 4, the experimental methodology. We list the results of the experiment in Part 5 and discuss them in Part 6. Finally, in Part 7 we draw conclusions and propose avenues for future research.

\section{Related Work}

\subsection{Virtual Environments for Heritage Learning}

Mortara \& Catalano [38] provide a thorough outline of the strengths of 3D virtual environments for cultural heritage learning, emphasising the ability of such environments to recreate an holistic experience of an historical setting, including the sights, sensations, and actors involved. They argue that immersion, accuracy and rigour, the completeness of the experience in an holistic world where there are many possibilities for interactions, and multi-sensory hardware, all create a positive experience in an heritage environment, although they also suggest that high-fidelity environments may not be necessary to achieve a strong sense of presence. Champion [39] describes many of the issues of current heritage virtual environments, claiming they lean too heavily on visualisation and presentation, rather than contextual understanding and experience. He argues for an approach whereby we must better understand our phenomenological and hermeneutical experiences of places before we can better reproduce these experiences through virtual environments. Falconer \& Scott [40] applied such a phenomenological approach to their evaluation of a virtual recreation of Avebury Henge, as well as a limited use of phenomenographical techniques. Through these methods they found that the virtual environment could achieve an experience of the archaeological site, but that experience was significantly different from the realworld experience of the modern-day site.

A small number of frameworks have been proposed in the literature for the design of virtual heritage environments. Bakar et al. [41] produced a set of guidelines on the design of such environments based on a series of interviews with field experts. These, they organised into content-related items, experience-related items, setting-related items, support-related items, and interface-related items. A framework for digital heritage interpretation, the process of learning, communicating, and managing heritage, was presented by Rahaman [42], developed through a literature review, which consists of four aspects: effective presentation, cultural learning, embodiment and embodied interaction, and dialogic interaction. Another framework for the design of virtual environments for heritage learning was presented by Ibrahim \& Ali [43], comprising four categories: 
pag. 96

environment setting and navigation mechanism (which alone form a 'virtual walkthrough'), and information presentation and information design (which facilitate the cultural learning). Their framework was developed through several stages of consultation, design, and review, and due to its recency and specificity, we consider it the current state-of-theart in virtual heritage environment design.

\subsection{Constrained Virtual Environments}

Constrained virtual environments are based on the theory of the "tourist gaze" [44], where to be a tourist is to view only a reduced, stage-managed set of highlights of a place. The tourist may feel they have achieved a strong sense of that place, even though they were only exposed to a small number of experiences over a short period. Turner et al. [45] argue that to experience a virtual environment is, in a sense, to be a tourist. They propose that a participant could similarly be exposed to a reduced set of virtual highlights and achieve the same sense of that place. Turner et al. [37] describe the development of a constrained virtual environment for giving a tourist an experience of the City of Edinburgh, formed from a series of 2D scenes. Each scene is formed from multiple photographic layers overlaid on top of one another, with a parallax effect as the use moves the cursor to give the illusion of a 3D scene. They also use visual techniques such as "chiaroscuro", the use of lighting within an image to give a sense of depth, rather than attempting to achieve photorealism [45]. The authors argue that when presented with a lower fidelity virtual environment, subjects cannot offload as much of the cognitive burden onto the environment and must make greater use of their own mental representations [37]. They base these proposals on their theory of "digital make-believe" [46], whereby an interaction with a virtual environment is really a session of make-believing; we are willing to pretend as though the environment were real, and engage with it using our mental schemata relevant to the subject matter. Furthermore, Turner [47] also argues that make-believe can even give an account of presence. Parallels are drawn between the effect of low-fidelity environments and the "book problem" [45], which refers to the paradoxical ability of books, one of the lowest fidelity media available, to create a strong and vivid sense of place for the reader. Finally, they argue that the greatest advantage of constrained environments is the reduced resources required when compared to an equivalent 3D environment [37].

\subsection{Presence, Cultural Presence, Sense of Place, and Immersion}

Presence, place, and immersion are all complex and multi-faceted concepts that have long been the subject of academic debate. In this section we will briefly review some of the concepts most relevant to this study and justify our choice of measuring presence within the game environments.

Presence is used to refer to an experience described as "being there" [48], a "psychological state where the virtuality of experience is unnoticed" [49], or the "perceptual illusion of non-mediation" [50], although many different definitions exist [51]. Despite the lack of a single agreed definition, methods for measuring presence are a welldeveloped field, with the most common approach being post-experience questionnaires [52]-[55]. Furthermore, presence has been used as the object of interest in many investigations with serious games and virtual environments for learning [56]-[58] as well as commercial video games [59], [60].

Cultural presence is one aspect of presence applied to virtual heritage projects and used to measure the extent to which the participant experiences and feels present within another culture. In this field, Champion and Pujol-Tost are prominent figures [61]-[63], having developed a definition of the concept as comprising three factors: cultural representation and engagement, social presence, and communicational aspects of technology [63]. They have also suggested ways of designing virtual heritage environments to maximise cultural presence [62]. However, validated methods for measuring cultural presence are not as well founded as in presence. 
Sense of place refers to the layers of context, affect, and significance placed upon our physical environments, expressed simply as "place $=$ space + meaning" [64]. Definitions have expressed sense of place as a multi-faceted concept with cognitive, conative, and affective dimensions [65]. It is often related to presence (one could express place as the "there" in "being there"), and even as a factor contributing to presence [66]. Indeed, some attempts by researchers to create a sense of place instrument directly utilise a presence questionnaire [67].

Immersion is a term that is understood very differently depending upon the context. Within the literature and industry of video games, immersion refers to a complex phenomenon related to presence, engagement, and flow, among others [68], yet it is also a word accepted, used, and understood by most players and game critics. Several different definitions and frameworks of immersion have been proposed [69]-[72], as well as measuring techniques based on self-evaluation [73] and physiological signals [72]. Such attempts at measurement have found that immersion positively affects learning in a serious game for science education [73], yet the lack of standardised and validated instruments makes it difficult to generalise such results. Furthermore, while many researchers have argued that presence is a component of immersion, Cairns et al. [74] showed experimental evidence that presence and immersion can be completely independent of one another. Finally, Zhang et al. [68] showed that, using the term "immersion" as a loose umbrella term for many inter-related concepts, emotional forms of immersion are far more effective than spatial forms of immersion at engaging the player and giving them a sense of "being there" in the game.

Taking the above points into consideration, presence will be used as the focus of interest within this study, due to its well-developed body of literature and experimental studies, and the numerous measurement instruments towards which validation efforts have been directed [51].

\section{Development of a Constrained Virtual Environment for Heritage Learning}

\subsection{Base 3D Environment}

Two versions of the serious game for heritage (SGH) Discover Babylon were released, a short "kiosk" version and a longer "full-game" version [33]. In the full-game version, the player must travel back in time to different periods of, and locations within ancient Mesopotamia. Here they are required to navigate and explore 3D environments representing Mesopotamian cities, and must talk to historical characters, trade goods, explore, and solve puzzles to continue the story and resolve the central dilemma. Such an environment is shown in the left-hand column of Figure 1. The player takes on the role of an historical actor and can move them within the environment space, using a third-person perspective camera suspended behind the player's avatar (sometimes referred to as a "tethered" form of navigation). Furthermore, there are ten information tokens hidden throughout each historical environment, visible in Figure 1c. When the player collects one, they are presented with an historical fact relating to the area of the environment in which the token was discovered. The player is also told how many tokens they have found, and how many remain, thereby encouraging exploration of the environment to collect them all. The game contains a very limited set of sounds, used for character dialogue, footsteps, when the player completes an objective, or when interacting with the UI. However, the environments themselves contain next to no ambient sound effects or ambient music. 


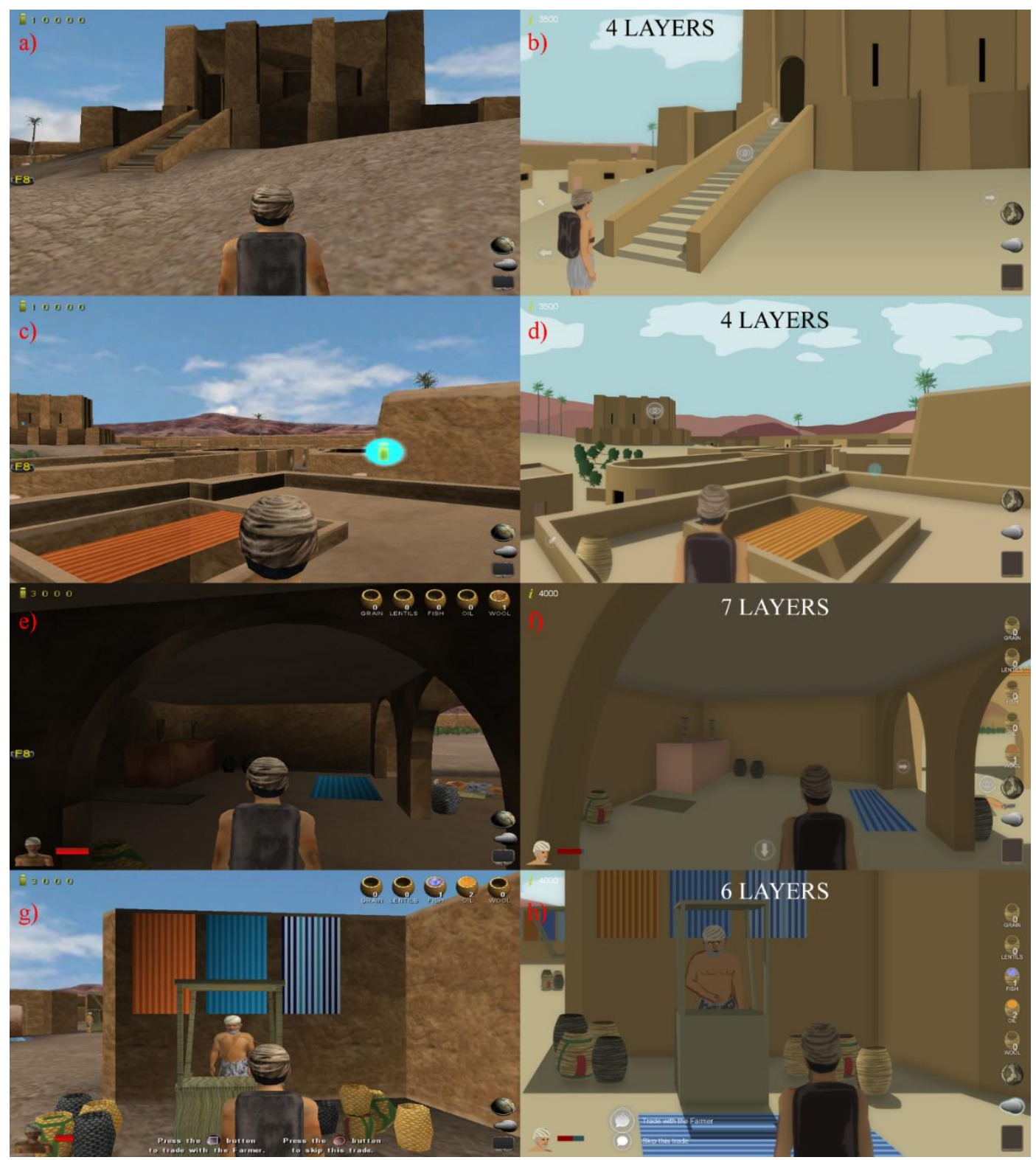

Figure 1. Left column shows screen captures from the Uruk environment of Discover Babylon [33], right column shows the corresponding area reproduced in the constrained environment (the number of layers in each scene is shown). A short comparison video can be viewed at "https://youtu.be/o0K419avYGc".

Printed with permission of Federation of American Scientists.

\subsection{The Developed Constrained Environment}

A constrained environment was developed, using the same characteristics as the environment described in [37], to reproduce the second level of Discover Babylon, set in the ancient Mesopotamian city of Uruk in 3200 BC, as well as all the story and gameplay elements contained within this level. A custom game engine was developed using the XNA game platform, which contained all the mechanics of a constrained environment, including layering and parallax effects. The engine accepts all game content as a series of XML, texture, and sound files, and therefore operates in a modular and reusable fashion. Development of constrained environments would also be possible using an off-the-shelf engine, depending on the features it offers, most notably the ability to create and apply customised shaders. The environment consists of a series of 2D scenes, each based on the 
tourist gaze principle, described earlier [45]. The engine additionally implemented a depthof-field effect, in that, as the cursor is moved across the scene, the depth of the point where the cursor is placed is stored. Any areas of the scene close to this depth will remain sharp and in focus, but any areas at a shallower or deeper depth will be rendered with a Gaussian blur shader, making them appear out of focus. Finally, the developed engine can also apply post-processing shaders to the entire scene, to simulate a chosen visual style. One style investigated was the watercolour painting shader detailed by Bousseau et al. [75].

The first step of the development of the constrained environment was to convert the $3 \mathrm{D}$ environment into a series of 2D scenes, implemented by charting the environment on paper and identifying the highlights and most notable areas. Some scenes were connected, representing where players can move between scenes. Each scene was sketched by stitching together screen captures from the 3D game, to give the player an impression of that area of the environment within a single view, and was then broken down into 2D layers, each a texture generated with typical desktop image manipulation software. Each scene was designed to maximise the use of layering and parallax, by placing items, buildings, and nonplayer characters (NPCs) at varying distances from the camera, to accentuate the illusion of a 3D scene, and each scene also maximised the use of chiaroscuro through intense lighting and shadowing. The developed constrained environment is shown alongside (for contrast) the corresponding areas of the Discover Babylon environment in Figure 1 and the features of the engine discussed in this section are shown in Figure 2. The developed constrained environment consisted of 30 navigable scenes, each utilising between 2 and 11 layers (median 5), excluding NPCs and characters. The development process took approximately 170 hours of labour, 130 of which were dedicated to developing the environment, and the remaining 40 to the implementation of the mechanics and logic of the level. This is significantly lower than what would typically be required to produce a similar $3 \mathrm{D}$ environment, although the process was expedited by only needing to implement the environment and mechanics and not design them. It was observed that developing the constrained environment required a similar set of skills as for 3D environments, although with more focus on 2D graphics and texture manipulation.

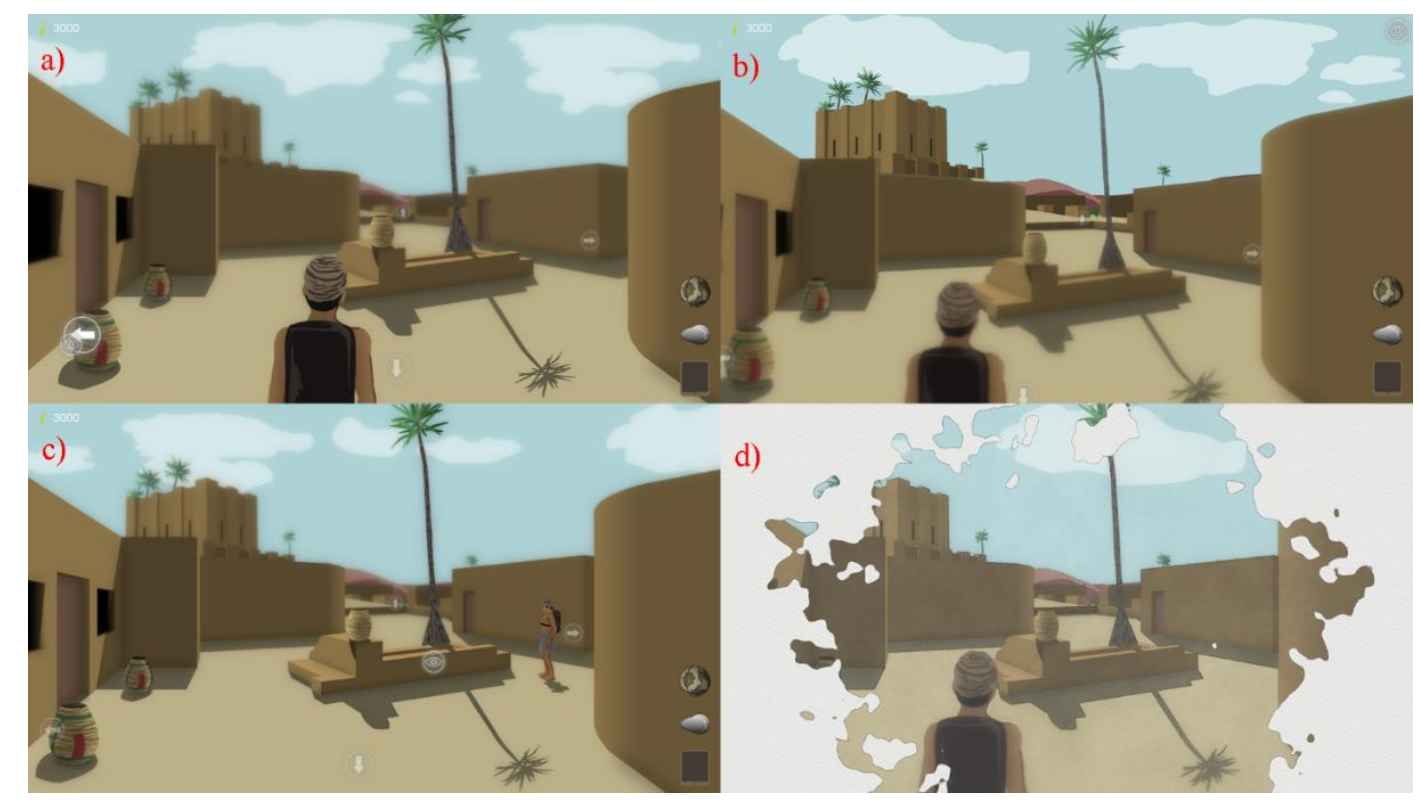

Figure 2. Screen captures from one scene of the constrained environment (each scene consists of 12 layers): a) cursor at the bottom-left of the screen, blurring the background; $b$ ) cursor at the top-right of the screen, shifting the parallax and blurring the foreground; c) moving to the scene from a different direction, changing the avatar position; d) using a watercolour post-processing effect. 
Environmental interactions are represented through icons at different locations in each scene, each with a corresponding symbol. The player moves the cursor with either the computer mouse or using a touch screen and moves between scenes by interacting with scene transition icons, shaped like arrows and placed at appropriate points throughout the scenes. When they do so, the scene fades out and the destination scene fades in, accompanied by the sound of footsteps, such that movement between scenes is not exhaustively modelled, it is merely suggested. The player's avatar can also be shown in multiple positions in each scene, and once in the destination scene, the player's avatar is shown in a position corresponding to the direction they came from, shown in Figure 2c. This third-person perspective, where the avatar is visible in each scene, was chosen to imitate the base game, although the distance between avatar and camera is greater. The consequences and alternatives of this decision will be considered further in Part 6 .

It must be stressed that the intention of the constrained environment implementation of the Uruk level is to only alter the mode of presentation of the environment and change the game mechanics as little as possible. This was achieved by converting each game mechanic into a natural equivalent in the constrained environment. For example, in the base game, when the player must pick up an object or information token, it is represented by a floating 3D token the player must move their avatar into. The analogue of this in the constrained environment was an icon located within the scene that the player must click to interact with. The base game also contained a limited NPC dialogue tree system, where the player could choose responses with a corresponding keyboard key. The constrained environment equivalent of this was "dialogue scenes" (for example Figure 1h) where responses are chosen by clicking a corresponding icon. Two 3D animated cutscenes in the base game were reproduced as $2 \mathrm{D}$ animated cutscenes using appropriate constrained environment scenes and character graphics. Finally, a tablet decipherment puzzle was recreated without alteration, since it was presented through 2D UI in the base game. All the game mechanics and logic of the Uruk level of Discover Babylon were simple enough to be thoroughly observed and documented in-game, and all the game sounds effects were also sampled and implemented in the constrained environment.

\subsection{Constrained Environment Presentation}

The visual style used for implementing the constrained environment was one of untextured blocks of colour, shaded based on lighting conditions, shown in the right-hand column of Figure 1, chosen to reduce the comparability with a photorealistic image, as detailed by Turner et al. [37]. In the current study we have not investigated using different visual styles, although this presents an interesting avenue for further research. Constrained environments may offer innovative methods to overcome some of the challenges of representation faced by SGsH, such as violence within the source material or uncertainty in the current state of historical knowledge [31], compounded by the expectation of younger participants that everything they see in the virtual environment is presented as it truly was [26]. These could be tackled using the fact that not everything is shown in exhaustive detail in a constrained environment; information can be obscured or only suggested to the user. Another possible approach is the blending of a constrained environment with 3D models of artefacts, which could be viewed and manipulated, while transposed on top of the 2D scene.

\section{Experiment}

\subsection{Experimental Methodology}

To investigate the feasibility of constrained virtual environments for serious games for heritage, an exploratory experiment was performed to compare the developed environment against the corresponding 3D level from Discover Babylon. The aim was to investigate differences in players' perceptions of the environments, specifically presence, their 
perception of the quality of the game, their exploration of the environment, and their subsequent interest in the subject matter, as well as highlighting issues and areas for further research. To address these areas of investigation, a two-group independent samples experiment was designed, where one group, hereafter known as the '3D Environment group', played the Uruk level from Discover Babylon, and the other group, hereafter known as the 'Constrained Environment group', played the constrained environment implementation of the same level. The logistical constraints of the experiment did not permit a matched-pair design; therefore, participants were randomly assigned to one group or the other.

Participants first completed a pre-game questionnaire, to collect demographic information, their educational discipline, their familiarity with Mesopotamian history, and how frequently they played video games. They were then given an information sheet to explain the narrative and how to interact with the game. Participants then played one version of the game, according to their experimental group, sitting at a desktop PC running the game in a quiet laboratory, with a large ultra-high definition ("4K") monitor and in-ear headphones. Participants in the 3D Environment group controlled the game avatar with a keyboard, using the arrow keys for movement and numpad keys for interactions. Participants in the Constrained Environment group used a trackball mouse to move the cursor, using the mouse button for interactions. The setup is shown in Figure 3 for the 3D Environment group. Although the input modality is not tested as an independent variable, it differs between the two versions of the game because each is the most natural control scheme to use with the corresponding environment type. It must be stressed that the aim of the experiment is to compare the two environment types as they would be implemented in the real world. Participants were instructed to undertake the game at their own pace, playing for as long as they wished.

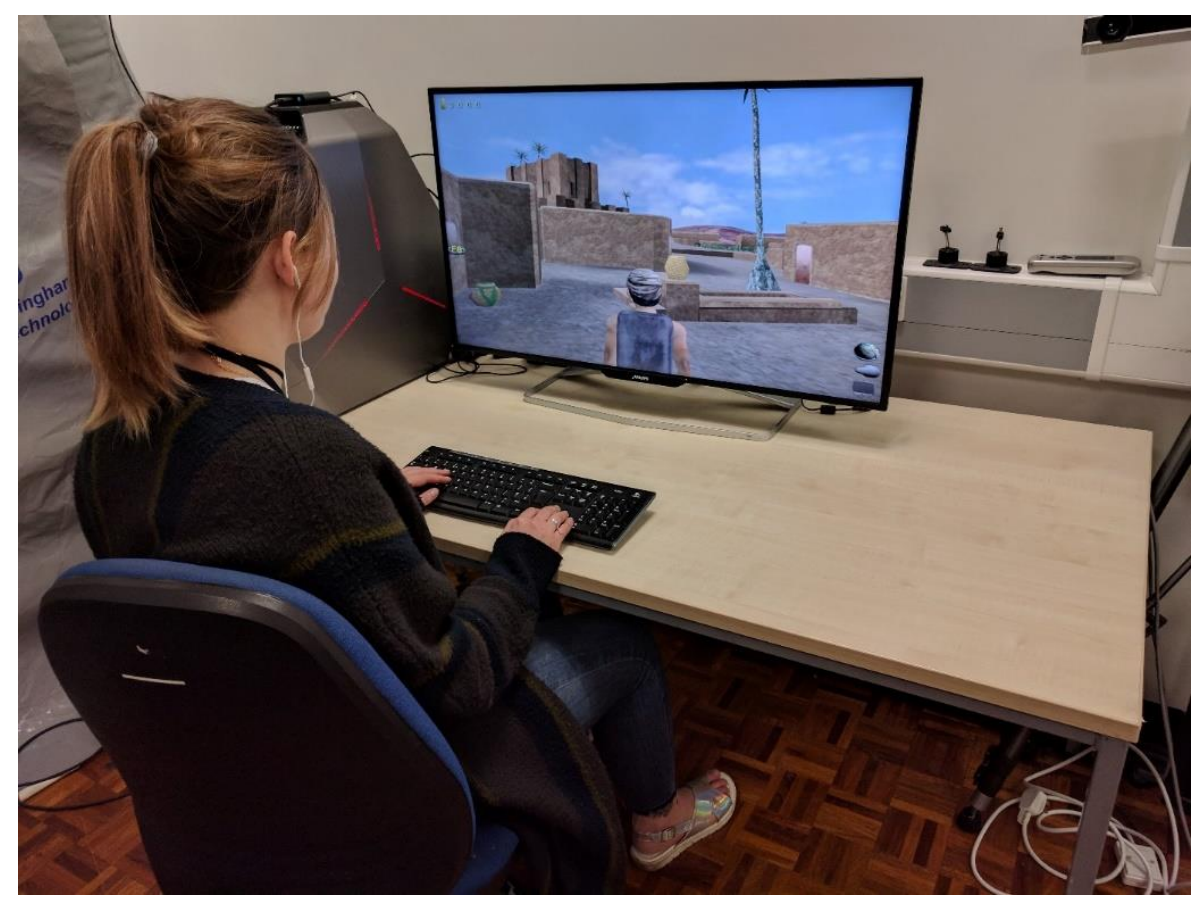

Figure 3. Experimental participant playing the $3 D$ version of Discover Babylon on a desktop PC with a large " $4 K$ " monitor, in-ear headphones, and keyboard.

While they were playing, silent observations were made of the participants' in-game and real-life behaviours, including how quickly they learned to interact with the game, how proficiently they could complete the challenges, and how many of the ten information tokens they collected from within the environment. After playing, participants completed a post-game questionnaire, measuring how much they enjoyed the game and how much it 
increased their interest in the subject matter on five-point Likert scales, and asking them to rate the game out of 10 in eight categories; navigation, sound, text, interactions, aesthetics, locations, characters, and engagement. Participants' experience of presence in the environment was also measured, using the Slater-Usoh-Steed presence instrument [53], chosen due to its extensive use by other presence researchers, its ease to be adapted to any virtual environment, and its short length, comprising only six seven-point Likert scale questions.

Afterwards, participants completed a short semi-structured interview, asking them to recount their experiences within the virtual environment, their personal styles of navigation, their motivation to collect the information tokens, and their most and least favoured aspects of the game. After the experiment was completed, participants were sent a short email, thanking them for their participation and providing several online links where they could learn more about the subject matter, in case the game had roused their interest. Three months after completing the experiment, participants completed another questionnaire online, asking them to re-rate how much their interest in the subject matter had been increased by playing the game, again on a five-point Likert scale, as well as asking them whether they had since taken any steps to learn more about ancient Mesopotamian history, or planned to do so.

\subsection{Pilot Test}

Five participants, all postgraduate students at the University of Birmingham, took part in a pilot test utilising the experimental methodology described above. The purpose of this pilot test was to trial the experimental procedures and to inform the design of the constrained environment. The resulting feedback prompted the addition of a feature whereby the position of the player's avatar in each scene changed based on the scene they had transitioned from, as described in Part 3.2. Two of the participants completed the 3D environment game, and so their data could be included in the cohort for the main stage of the experiment.

\subsection{Participants}

A further 32 participants were recruited, all undergraduate or postgraduate students at the University of Birmingham, forming a total cohort of 34 (with the two participants from the pilot test), 17 assigned to each experimental group. Participants were recruited through posters placed on noticeboards around the campus and through flyers handed out during a departmental lecture. Every participant completed the entire story aspect of the level, explored the environment to whatever extent they wanted, and completed the pre-game, post-game, and long-term questionnaires. Due to ethical and logistical constraints, the participants were all aged over 18 , somewhat older than the target audience of the game. This is a limitation that should be considered when regarding the results and is discussed further in Part 6.4. Finally, an expert in the field of digital technology in museum displays from Arts Council England was also invited to play the constrained environment version of the game and was interviewed to discuss their reaction to the game and the feasibility of implementing such games within museum displays.

\section{Results}

\subsection{Participant Characteristics}

In the 3D Environment group, participant ages ranged from 18 to 29, mean 22.6 and standard deviation 3.9 years. In the Constrained Environment group, participant ages ranged from 18 to 41 , mean 23.8 and standard deviation 6.4 years. The genders, educational 
disciplines, initial familiarity with the subject matter, and frequency of playing video games for the participants in each experimental group are shown in Figure 4.

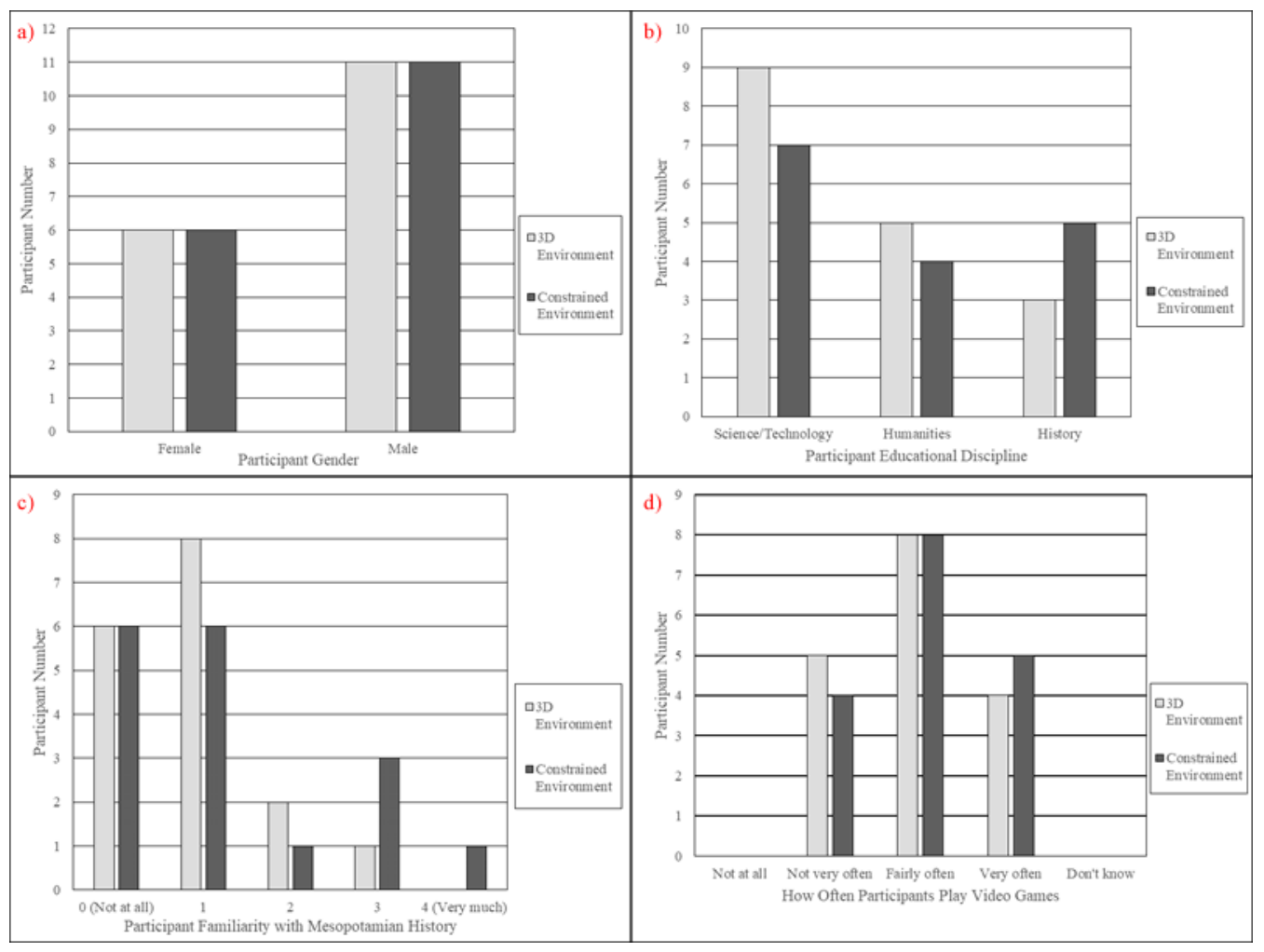

Figure 4. Distributions of participant characteristics across experimental groups: a) gender; b) educational discipline; c) familiarity with Mesopotamian history; d) frequency of playing video games.

\subsection{Presence}

Cronbach Alpha was calculated for the six questions of the Slater-Usoh-Steed presence instrument as 0.81 ("good" rating) for the 3D Environment group and 0.88 ("good" rating) for the Constrained Environment group. Mean presence ratings were calculated for each participant by coding the question Likert scales from 0 to 6 and calculating the mean of the six answers, the distributions for which are shown in Figure 5a.

A comparison of mean presence ratings between the two experimental groups was performed. The Shapiro-Wilk normality test found that neither the 3D Environment group, $\mathrm{W}(17)=0.96, \mathrm{p}>0.05$, nor the Constrained Environment group, $\mathrm{W}(17)=0.98, \mathrm{p}>0.05$, had a significantly non-normal distribution. Levene's test of the untransformed means found the variances for the two test conditions to be equal, $\mathrm{F}(1,32)=0.56, \mathrm{p}>0.05$. Therefore, an independent t-test was performed, and the difference was not significant, $t(32)=0.38, p>0.05$, with a negligible effect size, $r=0.07$. The $95 \%$ confidence interval corresponded to an inter-group difference of -0.94 to +0.65 .

During the interviews, when asked to recount their experience of the city of Uruk and whether they felt present or immersed within the environment, participants gave a range of responses. Several participants said they felt immersed because of the "task" or because of the "story and the goals", whereas one participant, CP01, noted the opposite effect: "The task overrode the feeling of being somewhere". One participant in the Constrained Environment group, TP01, spoke very positively of their feelings of presence and sense of place in the environment: "I felt like I am really in the city... although the graphic is not great compared to modern games, but it was really good, the feeling of the river, the feeling of the ziggurat... The experience, like I have been in the city. Yeah, I am walking in Uruk, 
pag. 104

it's real [laughs]". This participant said they were from Iraq and so felt a greater emotional connection with the environment.

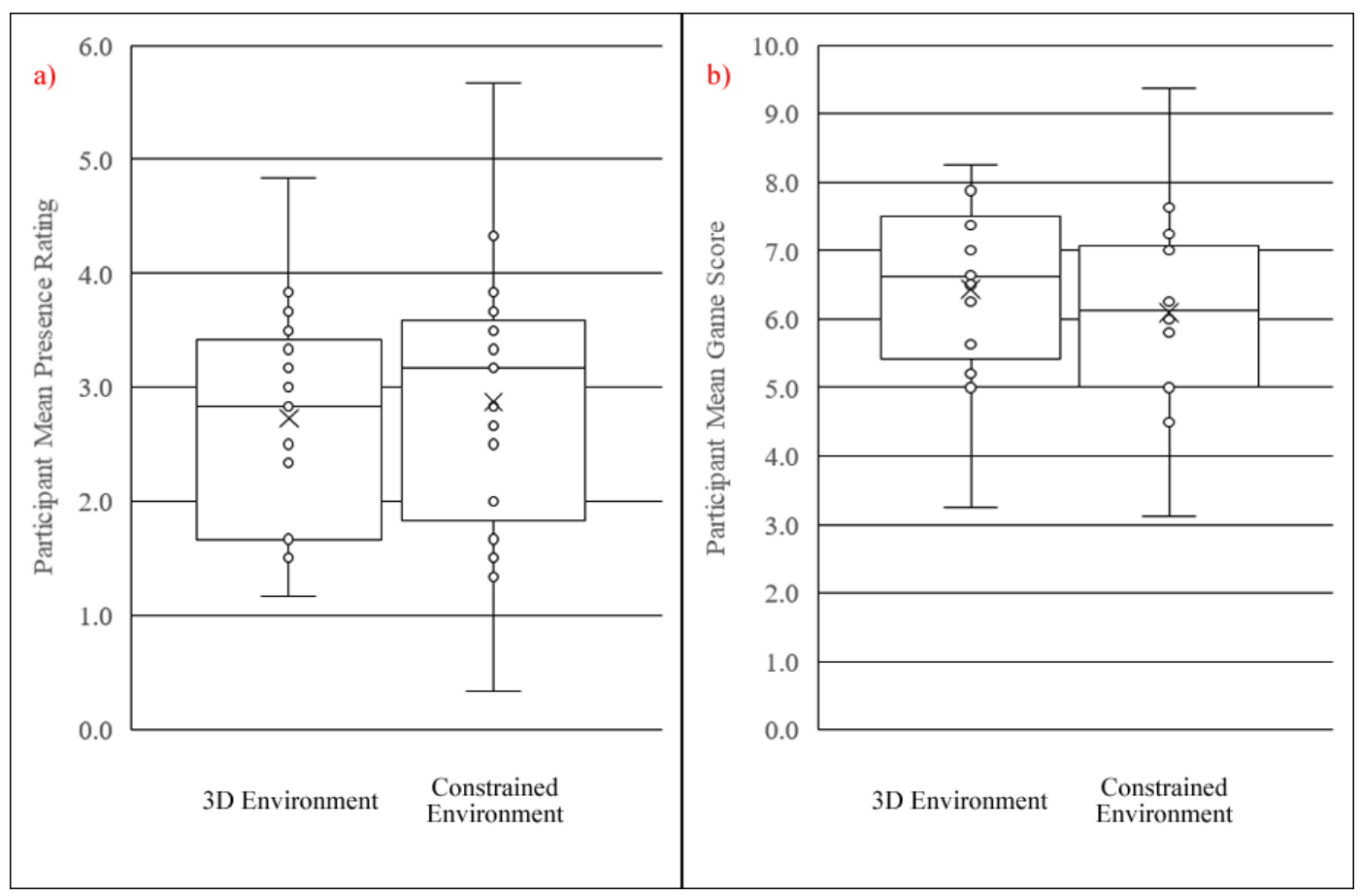

Figure 5. a) Box and whisker plots of mean presence rating across experimental groups; b) Box and whisker plots of mean game score across experimental groups.

\subsection{Game Scores}

The scores the participants assigned to the games are shown in Table 1, with means and standard deviations, across each category for the two experimental groups, as well as the mean of all eight categories, hereafter referred to as the "mean game score". The distributions of the mean game score for the two experimental groups are shown in Figure $5 b$.

Table 1. Scores out of 10 assigned to the game in eight categories, across experimental groups.

\begin{tabular}{c|c|c|c|c}
\hline \multirow{2}{*}{ Score Category } & \multicolumn{2}{|c|}{ 3D Environment Group } & \multicolumn{2}{c}{ Constrained Environment Group } \\
\cline { 2 - 5 } & Mean & Standard Deviation & Mean & Standard Deviation \\
\hline Navigation & 5.94 & 2.01 & 5.47 & 1.94 \\
\hline Sound & 6.65 & 2.00 & 5.94 & 2.22 \\
\hline Text & 7.29 & 1.83 & 7.65 & 1.62 \\
\hline Interactions & 7.12 & 1.27 & 6.82 & 1.78 \\
\hline Aesthetics & 5.94 & 1.56 & 5.71 & 1.96 \\
\hline Locations & 6.24 & 1.86 & 6.24 & 1.75 \\
\hline Characters & 6.41 & 1.62 & 5.12 & 1.73 \\
\hline Engagement & 7.35 & 1.69 & 6.94 & 1.89 \\
\hline Mean & $\mathbf{6 . 4 3}$ & $\mathbf{1 . 3 3}$ & $\mathbf{6 . 0 9}$ & $\mathbf{1 . 4 0}$
\end{tabular}

A comparison of mean game score for the two experimental groups was performed. The Shapiro-Wilk normality test found that neither the 3D Environment group, $D(17)=0.13, p$ $>0.05$, nor the Constrained Environment group, $\mathrm{D}(17)=0.11, \mathrm{p}>0.05$, were significantly non-normal. Levene's test of the untransformed means found the variances for the two test conditions to be equal, $\mathrm{F}(1,32)=0.00, \mathrm{p}>0.05$. Therefore, an independent $\mathrm{t}$-test was 
performed, and the difference was not significant, $\mathrm{t}(32)=0.81, \mathrm{p}>0.05$, the effect size was found to be small, $r=0.14$. The $95 \%$ confidence interval corresponded to an inter-group difference of -0.59 to +1.37 . The correlation between mean game score and mean presence rating was investigated, and a Person's R test found that mean game score was significantly correlated with the mean presence rating, $r=0.53, p=0.001$.

During the interviews, participants gave mixed responses when talking about the game they played. Within the Constrained environment group, participant TP06 wanted the graphics to be more "dynamic" and "3D" and participant TP08 said they were more used to 3D environments. However, TP17 stated that they found the game to be 3D instead of 2D, and TP05 spoke positively of the game's parallax effect: "I did kinda like as well that [the layers of the environment] moved with [the mouse cursor], it was a $2 \mathrm{D}$ drawing but it felt $3 \mathrm{D}$ at the same time, which made it more immersive I think".

\subsection{Information Token Collection}

During the game, participants in the 3D Environment collected a mean of 6.29 information tokens, standard deviation 2.52, whereas participants in the Constrained Environment collected a mean of 8.06 information tokens, standard deviation 2.08. The distributions of information token numbers for both experimental groups are shown in Figure 6a. A nonparametric comparison, using a Mann-Whitney U test, was performed and the number of information tokens collected in the 3D Environment did differ significantly from the Constrained Environment, $\mathrm{U}=81.50, \mathrm{z}=-2.21, \mathrm{p}<0.05$, and the effect size was medium, $r=-0.38$. When asked about the information tokens during the interviews, most of the participants described wanting to collect all of them (82\% 3D Environment, 88\% Constrained Environment, $85 \%$ overall), some even describing themselves as "completionists" or "collect-a-maniacs".

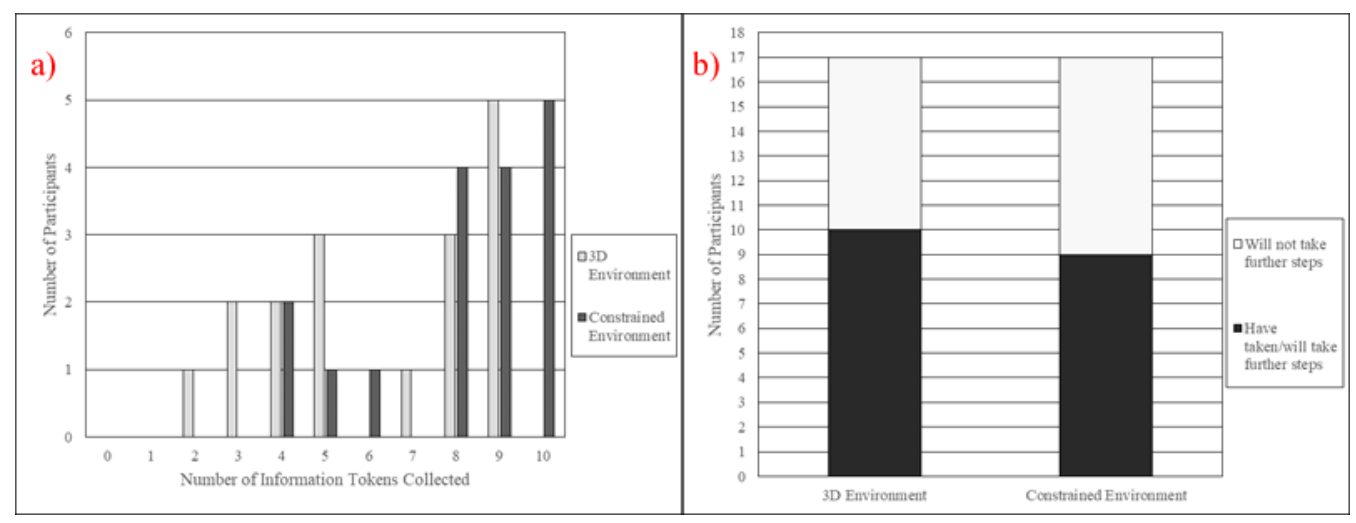

Figure 6. a) Distribution of numbers of information tokens collected, across experimental groups; $b$ ) Distribution of numbers of participants who pursued further information on the subject material, across experimental groups.

\subsection{Post-Game Interest in the Subject Material}

At the three-month follow-up stage of the experiment, 10 out of 17 participants (59\%) in the 3D Environment group and 9 out of 17 (53\%) in the Constrained Environment group stated that they had either sought out further information on Mesopotamian history or were planning to do so. These results are shown in Figure 6b. A Pearson Chi-Square test found no significant association between the experimental group the participant was assigned to and whether the participant took further steps to learn more, $\chi^{2}(1)=0.12, p>0.05$. Of those who said they had or would learn more, the most common method was reading web pages, although participants also mentioned books, documentaries, podcasts, and museum visits. To ascertain the factors that would encourage a participant to seek more information on the subject matter, a set of bi-serial correlations were performed, as shown in Table 2. 
Table 2. Biserial correlations between different variables and whether participants pursued further information on the subject material.

\begin{tabular}{c|c|c|c|c}
\hline Variable 1 & Variable 2 (Binary) & Test & $\begin{array}{c}\text { Test } \\
\text { Value }\end{array}$ & Significance \\
\hline $\begin{array}{c}\text { Initial familiarity with } \\
\text { subject }\end{array}$ & $\begin{array}{c}\text { Pursued further } \\
\text { information }\end{array}$ & $\begin{array}{c}\text { Spearman's } \\
\text { Rho }\end{array}$ & $\mathrm{r}_{\mathrm{s}}=0.16$ & $\mathrm{p}>0.05$ \\
\hline $\begin{array}{c}\text { Enjoyment of the game } \\
\text { information }\end{array}$ & $\begin{array}{c}\text { Spearman's } \\
\text { Rho }\end{array}$ & $\mathrm{r}_{\mathrm{s}}=0.02$ & $\mathrm{p}>0.05$ \\
\hline $\begin{array}{c}\text { Post-game interest } \\
\text { increase }\end{array}$ & $\begin{array}{c}\text { Spearman's } \\
\text { Rhformation }\end{array}$ & $\mathrm{r}_{\mathrm{s}}=0.36$ & $\mathbf{p}<\mathbf{0 . 0 5}$ \\
\hline $\begin{array}{c}\text { Long-term interest } \\
\text { increase }\end{array}$ & $\begin{array}{c}\text { Pursued further } \\
\text { information }\end{array}$ & $\begin{array}{c}\text { Spearman's } \\
\text { Rho }\end{array}$ & $\mathrm{r}_{\mathrm{s}}=0.55$ & $\mathbf{p}<\mathbf{0 . 0 5}$ \\
\hline Mean game score & $\begin{array}{c}\text { Pearson's R } \\
\text { Mursued further }\end{array}$ & $\mathrm{r}=0.22$ & $\mathrm{p}>0.05$ \\
\hline information & Pearson's R & $\mathrm{r}=0.04$ & $\mathrm{p}>0.05$ \\
\hline
\end{tabular}

\subsection{Participant Observations and Interviews}

While participants were playing the game, their in-game and real-life behaviours were silently observed. A general observation was that the participants in the 3D Environment group seemed to immediately recognise the tropes of the game and how to interact with them. Participants in the Constrained Environment group, however, had a greater learning curve to undergo and it took longer before they were as visibly comfortable and proficient at interacting with the game.

Participants' views of the game seemed (perhaps unsurprisingly) to be influenced by their expectations of modern games and by other games that they play. During the experiment, one participant, $\mathrm{CP} 03$, compared the graphics of the 3D Environment unfavourably to older hardware and games: "it's very 'Goldeneye', isn't it?". During the interviews, another participant from the 3D Environment group, CP10, stated that they are used to games such as Assassin's Creed and that this game was not what they were expecting, it was "different in many ways".

Finally, participants were asked what their most and least favoured aspects of the game they played were, and the results are shown in Table 3.

Table 3. Participant responses when asked for their most and least favoured aspects of the game they played, across experimental groups.

\begin{tabular}{c|c|c|c|c|c|c}
\hline \multirow{2}{*}{$\begin{array}{c}\text { Game } \\
\text { Aspect }\end{array}$} & \multicolumn{2}{|c|}{ One of Most Favoured Aspects } & \multicolumn{2}{c}{ One of Least Favoured Aspects } \\
\cline { 2 - 7 } & $\begin{array}{c}3 \boldsymbol{D} \\
\text { Environment }\end{array}$ & $\begin{array}{c}\text { Constrained } \\
\text { Environment }\end{array}$ & Overall & $\begin{array}{c}3 \boldsymbol{B} \\
\text { Environment }\end{array}$ & $\begin{array}{c}\text { Constrained } \\
\text { Environment }\end{array}$ & Overall \\
\hline Tablet puzzle & $1 / 17(6 \%)$ & $2 / 17(12 \%)$ & $9 \%$ & 0 & $1 / 17(6 \%)$ & $3 \%$ \\
\hline $\begin{array}{c}\text { Time } \\
\text { pressure }\end{array}$ & $4 / 17(24 \%)$ & $1 / 17(6 \%)$ & $15 \%$ & 0 & $2 / 17(12 \%)$ & $6 \%$ \\
\hline $\begin{array}{c}\text { Graphics } \\
\text { Voices }\end{array}$ & $1 / 17(6 \%)$ & $2 / 17(12 \%)$ & $9 \%$ & $3 / 17(18 \%)$ & $3 / 17(18 \%)$ & $18 \%$ \\
\hline $\begin{array}{c}\text { Market } \\
\text { interactions }\end{array}$ & $4 / 17(24 \%)$ & $4 / 17(24 \%)$ & $24 \%$ & 0 & 0 & $0 \%$ \\
\hline $\begin{array}{c}\text { Learning } \\
\text { Character } \\
\text { movement }\end{array}$ & $9 / 17(53 \%)$ & $10 / 17(59 \%)$ & $56 \%$ & 0 & 0 & $0 \%$ \\
\hline Navigation & 0 & 0 & $0 \%$ & $11 / 17(65 \%)$ & 0 & $33 \%$ \\
\hline $\begin{array}{c}\text { No musicl } \\
\text { ambient } \\
\text { sound }\end{array}$ & 0 & 0 & $0 \%$ & $3 / 17(18 \%)$ & $4 / 17(24 \%)$ & $21 \%$ \\
\hline
\end{tabular}




\subsection{Museum Expert Interview}

A museum expert from Arts Council England was invited to play the constrained environment game and be interviewed to ascertain the feasibility of implementing such games within physical museum displays. The expert had worked in Museum Insurance and Accreditation for six years, involving visiting museums across the country, and was actively interested in how museums use technology and interactive displays, commenting that when technology is implemented well in museums, it is implemented very well indeed and can be highly successful.

Overall, the expert felt very positive about the idea of implementing such a game in a museum space and was very supportive of using games in museums. Such institutions must adapt to and reflect the public that they serve and the greatest challenge of implementing any games is the resources required. For a museum, this cost must be considered for the entire lifecycle of the game, for equipment, design, development, and maintenance. There is interest and appetite for games among museums in the UK. However, austerity cuts and staff shortages make their use more difficult. The other principle challenge is the tone of the game, that the game is targeted at the same audience in the same manner as the rest of the museum displays. The game should be well-integrated into the rest of the museum, and not simply an add-on. This, of course, depends on the style of the museum and the tone they are trying to achieve.

\section{Discussion}

\subsection{Discussion of Experimental Results}

Mean sense of presence ratings amongst the Constrained Environment group were slightly higher than the 3D Environment group, but not significantly so. Furthermore, the confidence intervals are relatively narrow; we can say with $95 \%$ confidence that the $3 \mathrm{D}$ environment version of the game is no more than 0.65 points better on the seven-point Slater-Usoh-Steed scale than the constrained environment. Additionally, some of the interview responses suggested the constrained environment could create a strong sense of a historical place, if it engages participants emotionally, an observation supported by prior research [68]. However, the differing responses to the topic of presence and immersion in the interviews show the complexity of these concepts and how differently people can understand the terms within common parlance, highlighting the importance of standardised instruments such as the Slater-Usoh-Steed questionnaire when investigating such concepts. It is unknown to what extent the third-person perspective in the constrained environment may have negatively affected presence, given that several participants noted confusion or difficulties navigating with the given camera placements and perspectives. The selection of camera type (first- or third-person), placement, and perspective is therefore an important aspect that must be carefully considered throughout the design of a constrained virtual environment.

Mean game score was higher in the 3D Environment group, although not significantly so. Again, the confidence intervals were relatively narrow, such that there is a $95 \%$ confidence that the $3 \mathrm{D}$ environment game is perceived as being no more than 1.37 points better, on a scale out of 10, than the constrained environment game. It is interesting that perceived quality is correlated with presence, although of course the nature of causality is unclear.

Participants collected significantly more information tokens in the constrained environment than in the 3D environment. It is believed this is due to movement within the $3 \mathrm{D}$ environment being inherently slower and finding the information tokens in the constrained environment being easier, by exhaustively visiting every scene. Additionally, some of the tokens in the 3D environment were placed in locations that required skilled control of the character to reach, which caused some participants to simply give up. Despite 
this, there was a clear majority of participants who felt they wanted to collect all the tokens. This desire to complete collection tasks with only intrinsic rewards is an interesting phenomenon that should be utilised more as a source of motivation for completing serious game learning activities. However, the extent to which finding more tokens results in greater learning of the subject matter is a topic for further investigations.

There was no significant difference of whether participants from the two groups took further steps to learn more, and it is encouraging to see how many participants took these further steps, and the wide range of further learning activities, considering this was a completely voluntary activity. It is also interesting to note that none of the tested characteristics of the game were correlated with further learning. Based on the points discussed, we conclude that constrained environments are at least a promising avenue for research and are worthy of further investigation.

\subsection{Discussion of Participant Observations and Interviews}

Overall, there were some positive responses to the constrained environments, specifically its parallax effects. However, for some participants the constrained environment did not sufficiently recreate the experience of a 3D environment. It was also apparent that participants felt less comfortable and familiar with the interactions of the constrained environment. It might therefore be advisable to pay additional attention to the onboarding section of the game in a constrained environment, where the player is gradually taught the interactions and mechanics through hints or tutorials.

As was expected, participants' expectations are clearly influenced by the commercial games they play. However, this is an unavoidable fact of serious game development, and it is proposed that constrained environments, by utilising graphics less similar to high-fidelity 3D commercial games, might reduce unfavourable comparisons. Furthermore, 3D graphics are quickly superseded by the new state-of-the-art, and as such, serious games utilising such environments have a shorter lifecycle, as the participant's unfavourable comparisons with old gaming technology, such as the Nintendo 64, show.

It is apparent that many aspects of the game's design were divisive, which some players liked and some disliked, although this was seen in both the 3D and constrained environment versions of the game. A typical approach to address this issue may be to simply introduce more variety and optional content into the game. However, this approach will likely require more development resources, so a sensible balance must be reached. It is also encouraging that over half of the participants stated that learning was one of their favourite aspects. Finally, ambient sound and music is one aspect of virtual environments that can be overlooked within the development process (where programming and visual assets can take precedence) yet is an important aspect of presence [76] and its absence is noticed by players, as was discovered.

\subsection{Discussion of Museum Expert Interview}

Many of the points raised by the museum expert could equally apply to the application of other (non-constrained) virtual environments in museum contexts, however the fact that limited budgets and resources were identified as the greatest challenge for SGsH in museums confirms the necessity of the current research approach, and it was encouraging to hear the positive reaction to games utilising constrained environments being installed in museum displays. The expert's comments on matching the tone of the game to the surrounding museum displays is informative for serious game designers, showing the importance of keeping the directions of design closely aligned. However, there was no discussion of the game being implemented within a museum online setting, as the expert's experience was with physical displays. 


\subsection{Limitations of the Experiment}

The number of participants who took part in the experiment was not high enough to claim to have provided conclusive evidence of the equivalence of $3 \mathrm{D}$ and constrained environments, but rather to have shown where future work can continue this approach. Furthermore, while the Slater-Usoh-Steed presence instrument produces quantitative, easily comparable data, there is clearly information regarding participants' experience of these historical places that cannot be measured only through spatial presence, though this is clearly a larger issue faced by the field that can only be addressed through further research.

It is difficult to ascertain how far the results of the present study are generalisable to other serious games with different designs and integration of instructional content from different fields of cultural heritage. Some informational content may simply lend itself better to the format of constrained environments, so the appropriateness of the format must be carefully considered for the project in question. Furthermore, as discussed in Part 3.3, the constrained environment was developed with a specific visual style, selected due to development constraints and to reduce the comparability of the environment with a photorealistic representation. However, in the field of cultural heritage, where accuracy and authenticity are a vital component of any manifested information, we must be careful as to the extent to which we allow serious games to diverge from representing information as accurately as possible.

Finally, the original Discover Babylon game was targeted at younger players up to 14 years old, however the participants were all aged 18 or older, due to logistical constraints and the required ethics of performing experiments with minors. However, the purpose of the experiment was not to test the game within its target audience, but rather to test the principles of constrained virtual environments, and older participants allowed more detailed and articulate responses to be collected, especially in the interviews.

\subsection{Guidelines for Designing Constrained Virtual Environments for Heritage Learning}

By considering all the experiences of designing the constrained environment, conducting the experiment, and the issues encountered, we evaluated which design methods were effective and began drawing together a set of guidelines for designing constrained environments for SGsH. Since the implementation of the constrained environment was only focused on setting and navigation, and the informational content was recreated without alteration, the guidelines correspond to the first two stages of Ibrahim \& Ali's [43] model, namely environment setting and navigation mechanism. The guidelines are shown in Table 4 , categorised according to these two stages. Where possible, each guideline is shown adjacent to the corresponding issue encountered throughout the design and experimentation processes. It must be stressed that these early guidelines are not intended to be a formal theoretical framework for the SGH design and development process. 
Table 4. Early guidelines for the design of constrained environments for $S G s H$, based on experiences and issues during the described project. Rows in regular font apply specifically to constrained environments, rows in italics can apply to all environment types.

\begin{tabular}{|c|c|c|}
\hline Observed Issue & Design Guideline & In-Game Example \\
\hline \multicolumn{3}{|c|}{ Environment Setting } \\
\hline $\begin{array}{l}\text { Some participants had } \\
\text { difficulty navigating and } \\
\text { getting to where they } \\
\text { wanted to go. Some } \\
\text { participants could not } \\
\text { achieve a sense of spatial } \\
\text { awareness and visualise } \\
\text { where they were in the } \\
\text { environment. }\end{array}$ & $\begin{array}{l}\text { Show large, recognisable landmarks } \\
\text { in multiple scenes, so that players } \\
\text { can build up a sense of the } \\
\text { environment and navigate relative to } \\
\text { those landmarks. }\end{array}$ & $\begin{array}{l}\text { Large natural features or architecture } \\
\text { are effective for this. In the Uruk } \\
\text { environment, the Ziggurat and temple } \\
\text { were tall, dominant buildings in the } \\
\text { centre of the map. Showing these in } \\
\text { the background of as many scenes as } \\
\text { possible may help players to navigate, } \\
\text { using them as reference points. }\end{array}$ \\
\hline $\begin{array}{l}\text { Some participants found } \\
\text { that every part of the } \\
\text { environment looked too } \\
\text { similar, in style and } \\
\text { colour. }\end{array}$ & $\begin{array}{l}\text { Make different segments of the } \\
\text { environment look (and sound) } \\
\text { unique, so that players can more } \\
\text { easily recognise where they are. } \\
\text { This will also add more variety and } \\
\text { interest to the environment. }\end{array}$ & $\begin{array}{l}\text { Make each segment of the environment } \\
\text { unique using different environmental } \\
\text { colour palettes, NPCs, litter objects, } \\
\text { and ambient sounds, depending on } \\
\text { what is most appropriate for the } \\
\text { historical material. Also ensure that no } \\
\text { two scenes look too similar and could } \\
\text { be confused for one another. }\end{array}$ \\
\hline \multirow{2}{*}{$\begin{array}{l}\text { Some participants found } \\
\text { the environment too } \\
\text { "quiet" and "empty". }\end{array}$} & $\begin{array}{l}\text { Maximise the use of NPCs, litter } \\
\text { objects, and ambient sounds } \\
\text { throughout the environment. }\end{array}$ & $\begin{array}{c}\text { Populate the environments with NPCs } \\
\text { who would live or work there, objects } \\
\text { that would be used there, and the } \\
\text { sounds of the activities carried out } \\
\text { there. }\end{array}$ \\
\hline & $\begin{array}{l}\text { Take advantage of constrained } \\
\text { environments' ability to suggest } \\
\text { detail without showing it } \\
\text { exhaustively. }\end{array}$ & $\begin{array}{l}\text { A busy scene of people and activities } \\
\text { can be suggested by only showing } \\
\text { glimpses of it, or shown in the } \\
\text { background, accompanied by relevant } \\
\text { ambient sounds. }\end{array}$ \\
\hline \multirow{2}{*}{$\begin{array}{l}\text { Some participants found } \\
\text { the graphics too "static" } \\
\text { or not "dynamic" } \\
\text { enough. Some } \\
\text { participants found the } \\
\text { graphics too "flat" or not } \\
\text { "3D" enough. }\end{array}$} & $\begin{array}{l}\text { Maximise the use of depth layering, } \\
\text { thereby maximising parallax and } \\
\text { depth of field effects, and } \\
\text { chiaroscuro lighting within each } \\
\text { scene. }\end{array}$ & $\begin{array}{l}\text { Use many layers at different distances } \\
\text { from the camera and maximise } \\
\text { differences in lighting with bright light } \\
\text { sources and shadows. However, ensure } \\
\text { that layers cannot overlap each other in } \\
\text { illogical ways as they move through } \\
\text { parallax. }\end{array}$ \\
\hline & $\begin{array}{l}\text { Maximise the use of animated } \\
\text { objects within each scene. }\end{array}$ & $\begin{array}{c}\text { Add animations to background objects, } \\
\text { such as moving water or cloth that } \\
\text { moves in the wind. }\end{array}$ \\
\hline- & $\begin{array}{l}\text { Carefully consider the total number } \\
\text { of scenes used to present the } \\
\text { environment, given its size and } \\
\text { complexity. }\end{array}$ & $\begin{array}{c}\text { More scenes may aid the player's } \\
\text { sense of exploration and navigational } \\
\text { control over the environment, as well } \\
\text { as spatial presence. However, too } \\
\text { many scenes may also prove confusing } \\
\text { or frustrating, or may necessitate use } \\
\text { of navigation aids. More scenes also } \\
\text { increases the required development } \\
\text { resources. }\end{array}$ \\
\hline- & $\begin{array}{l}\text { Design the environment to take } \\
\text { advantage of players' curiosity and } \\
\text { internal motivation to explore. }\end{array}$ & $\begin{array}{l}\text { Design each scene so that the } \\
\text { transitions to other scenes invite } \\
\text { curiosity and preferably infer an } \\
\text { interaction with the environment, e.g. } \\
\text { walking up a set of stairs or opening a } \\
\text { door. }\end{array}$ \\
\hline- & $\begin{array}{l}\text { Scatter "collectibles" and } \\
\text { "achievements" through the } \\
\text { environment to encourage players } \\
\text { to explore all of the content. }\end{array}$ & $\begin{array}{c}\text { Track how many NPCs the player has } \\
\text { talked to or how much information } \\
\text { they have collected from the } \\
\text { environment, and show this progress, } \\
\text { indicating whether they have found } \\
\text { everything. }\end{array}$ \\
\hline
\end{tabular}




\begin{tabular}{|c|c|c|}
\hline \multicolumn{3}{|c|}{ Navigation Mechanism } \\
\hline $\begin{array}{l}\text { Many participants had } \\
\text { difficulty navigating and } \\
\text { getting to where they } \\
\text { wanted to go. }\end{array}$ & $\begin{array}{l}\text { Consider carefully whether the } \\
\text { player should be given additional } \\
\text { cues to aid in navigation, such as a } \\
\text { map, a compass, or an arrow } \\
\text { pointing to the next objective. }\end{array}$ & $\begin{array}{l}\text { These navigational aids can be shown } \\
\text { permanently on the HUD or made } \\
\text { visible with a button press. Such } \\
\text { features should be carefully designed } \\
\text { such that they do not reduce player } \\
\text { desire to explore. }\end{array}$ \\
\hline $\begin{array}{l}\text { Many participants were } \\
\text { unsure of their current } \\
\text { objective, or what they } \\
\text { should be doing. }\end{array}$ & $\begin{array}{c}\text { Consider whether the player should } \\
\text { be shown the current and completed } \\
\text { objectives. }\end{array}$ & $\begin{array}{l}\text { The objectives could be shown } \\
\text { permanently or made visible with a } \\
\text { button press. Objectives could also } \\
\text { contain hints for what the player } \\
\text { should do next. }\end{array}$ \\
\hline $\begin{array}{l}\text { Some participants found } \\
\text { the changes of camera } \\
\text { angle between scenes } \\
\text { unnatural or wanted to } \\
\text { control the camera. }\end{array}$ & $\begin{array}{l}\text { Decide early on whether the scenes } \\
\text { are equivalent to a 1st person or 3rd } \\
\text { person perspective. Design each } \\
\text { scene so that the position and angle } \\
\text { of the camera corresponds logically } \\
\text { to a person moving through that } \\
\text { environment. Consider the effect of } \\
\text { first- and third-person perspectives } \\
\text { on players' sense of spatial } \\
\text { awareness and ability to navigate } \\
\text { [59]. }\end{array}$ & $\begin{array}{l}\text { Draw a plan view of the environment, } \\
\text { chart how a character might move } \\
\text { through it, and design the camera } \\
\text { placement for each scene to } \\
\text { correspond naturally to this movement, } \\
\text { without disorienting changes in } \\
\text { position or angle. Consider also } \\
\text { whether each area of the environment } \\
\text { should contain several scenes } \\
\text { corresponding to different camera } \\
\text { positions, however be aware of the } \\
\text { additional development cost this } \\
\text { entails. }\end{array}$ \\
\hline $\begin{array}{l}\text { Some participants were } \\
\text { unaware that they were } \\
\text { playing as their avatar. }\end{array}$ & $\begin{array}{l}\text { If using a 3rd person perspective, } \\
\text { the player avatar should be shown, } \\
\text { able to move within and interact } \\
\text { with the scene. }\end{array}$ & $\begin{array}{l}\text { When the player interacts with an } \\
\text { element in the scene, the avatar should } \\
\text { then be shown moving to that element } \\
\text { and interacting with it. }\end{array}$ \\
\hline $\begin{array}{l}\text { Many participants felt } \\
\text { somewhat less } \\
\text { comfortable with the } \\
\text { constrained environment } \\
\text { compared with } 3 D \\
\text { environments. }\end{array}$ & $\begin{array}{l}\text { Gradually introduce the player to } \\
\text { the mechanics for moving and } \\
\text { navigating within the environment } \\
\text { during an on-boarding segment. } \\
\text { Hodent [77] gives advice for the } \\
\text { design of onboarding in video } \\
\text { games from a user experience } \\
\text { perspective. }\end{array}$ & $\begin{array}{l}\text { This on-boarding segment could be a } \\
\text { small, self-contained "starting area" } \\
\text { of the environment where the players } \\
\text { can learn and familiarise themselves } \\
\text { with the mechanics before starting the } \\
\text { main portion of the game. }\end{array}$ \\
\hline
\end{tabular}

\section{Conclusions and Future Work}

This paper has detailed the proposition of utilising constrained virtual environments for serious games for heritage, primarily to help reduce the required development cost which can be a challenge for cultural institutions such as museums. It described the development of a constrained environment implementation of a navigable 3D environment from the game Discover Babylon, which required significantly fewer resources, and similar skills, to what an equivalent 3D environment would involve. A two-group experiment comparing the two versions of the game provided evidence that the constrained and 3D environments could achieve similar levels of presence and were perceived by players as being of similar levels of quality. Many of the participants felt intrinsically motivated to collect all the information tokens from within the environment, and participants collected significantly more from the constrained environment, likely due to the collection activity being inherently easier. Many participants found that the game increased their level of interest in Mesopotamian history and were motivated to perform their own further learning, and participants who played the 3D or constrained environment were not significantly different in this regard.

An interview with a museum expert provided positive feedback for the potential use of SGsH utilising constrained virtual environments within physical museum displays and confirmed that cost is the greatest challenge that must be overcome to implement such games. Furthermore, these processes have revealed many of the issues and challenges unique to designing constrained environments for heritage settings. These have been 
distilled into a set of guidelines, which can now be used to aid other researchers and practitioners alongside other frameworks for heritage environment design. These guidelines are the first step towards forming a more comprehensive framework for designing constrained environments for SGsH. Finally, this project has provided evidence that constrained virtual environments can be a viable approach for the design of serious games for heritage, although further research is required.

Such further research includes experimentation with larger cohorts (of various ages) to determine to what extent constrained environments can convey historical places and their cultural context, compared with 3D environments and traditional forms of learning. Such investigations could investigate participants' phenomenological experience of those historical places and should include an analysis of learning effectiveness, especially spatial information that is manifested through the environment itself. Work could also address the effects of different visual styles within constrained virtual environments, their effects on player perceptions and historical learning, and how heritage information can be manifested differently through those visuals. Finally, future work should also design new serious games for heritage built upon the concept of constrained environments from the initial design phases. Such projects can aim to build upon and expand the guidelines presented in this paper, especially considering how heritage information should best be designed and manifested through a constrained environment. This would address the final two stages of Ibrahim \& Ali's [43] framework (namely Information Presentation and Information Design) and so would work towards a more complete framework for the design of constrained virtual environments for heritage learning.

\section{Acknowledgements}

The experiment detailed in this paper received full ethical approval from the Science, Technology, Engineering and Mathematics Ethical Review Committee at the University of Birmingham under application ERN_15-1701. We wish to extend our gratitude to all the participants who took part in the experiment, especially the member of Arts Council England who agreed to share their valuable time and experience with us.

\section{References}

[1] M. B. Carvalho et al., "An activity theory-based model for serious games analysis and conceptual design,” Comput. Educ., vol. 87, pp. 166-181, 2015. https://doi.org/10.1016/j.compedu.2015.03.023

[2] M. J. Dondlinger, "Educational Video Game Design: A Review of the Literature," J. Appl. Educ. Technol., vol. 4, no. 1, pp. 21-31, 2007.

[3] P. Siriaraya, V. Visch, A. Vermeeren, and M. Bas, "A cookbook method for Persuasive Game Design," Int. J. Serious Games, vol. 5, no. 1, pp. 37-71, 2018. https://doi.org/10.17083/ijsg.v5i1.159

[4] S. Kim, M. Chang, K. Deater-Deckard, M. A. Evans, A. Norton, and Y. Samur, "Educational games and students' game engagement in elementary school classrooms," J. Comput. Educ., vol. 4, no. 4, pp. 395-418, 2017. https://doi.org/10.1007/s40692-017-0095-4

[5] E. A. Boyle et al., "An update to the systematic literature review of empirical evidence of the impacts and outcomes of computer games and serious games," Comput. Educ., vol. 94, pp. 178$192,2016$.

[6] C. E. Catalano, A. M. Luccini, and M. Mortara, "Best Practices for an Effective Design and Evaluation of Serious Games," Int. J. Serious Games, vol. 1, no. 1, 2014.

[7] M. Freire, Á. Serrano-Laguna, B. Manero, I. Martínez-Ortiz, P. Moreno-Ger, and B. FernándezManjón, "Game Learning Analytics: Learning Analytics for Serious Games," in Learning, Design, and Technology, Cham: Springer International Publishing, 2016, pp. 1-29. 
[8] C. Girard, J. Ecalle, and A. Magnan, "Serious games as new educational tools: How effective are they? A meta-analysis of recent studies," J. Comput. Assist. Learn., vol. 29, no. 3, pp. 207219, 2013. https://doi.org/10.1111/j.1365-2729.2012.00489.x

[9] K. van der Kooij, E. Hoogendoorn, R. Spijkerman, and V. Visch, "Validation of Serious Games," Int. J. Serious Games, vol. 2, no. 3, pp. 63-75, 2015. https://doi.org/10.17083/ijsg.v2i3.75

[10]C.-H. Wu, Y.-L. Tzeng, and Y. M. Huang, "Understanding the relationship between physiological signals and digital game-based learning outcome," J. Comput. Educ., vol. 1, no. 1, pp. 81-97, 2014. https://doi.org/10.1007/s40692-014-0006-x

[11] L. Moller and P. K. Hansen, "Framing Serious Games Development as a matter of business," Int. J. Serious Games, vol. 3, no. 1, pp. 33-40, 2016.

[12]E. F. Anderson, L. McLoughlin, F. Liarokapis, C. Peters, P. Petridis, and S. de Freitas, "Developing serious games for cultural heritage: A state-of-the-art Review," Virtual Real., vol. 14, no. 4, pp. 255-275, 2010. https://doi.org/10.1007/s10055-010-0177-3

[13] M. Mortara, C. E. Catalano, F. Bellotti, G. Fiucci, M. Houry-Panchetti, and P. Petridis, "Learning cultural heritage by serious games," J. Cult. Herit., vol. 15, no. 3, pp. 318-325, 2014. https://doi.org/10.1016/j.culher.2013.04.004

[14] A. Antoniou, G. Lepouras, S. Bampatzia, and H. Almpanoudi, “An Approach for Serious Game Development for Cultural Heritage: Case Study for an Archaeological Site and Museum," J. Comput. Cult. Herit., vol. 6, no. 4, p. 17.1-17.19, 2013.

[15]F. Bellotti, R. Berta, A. De Gloria, A. D’ursi, and V. Fiore, “A serious game model for cultural heritage," J. Comput. Cult. Herit., vol. 5, no. 4, p. 17.1-17.27, 2012.

[16]F. M. Dagnino, F. Pozzi, E. Yilmaz, N. Grammalidis, K. Dimitropoulos, and F. Tsalakanidou, "Designing Serious Games for ICH education," in Digital Heritage, 2015, vol. 2, pp. 615-618.

[17] A. Doulamis, F. Liarokapis, P. Petridis, and G. Miaoulis, "Serious games for cultural applications," in Intelligent Computer Graphics 2011, D. Plemenos and G. Miaoulis, Eds. Berlin, Heidelberg: Springer, 2012, pp. 97-115. https://doi.org/10.1007/978-3-642-22907-7_6

[18]I. Paliokas and S. Sylaiou, "The use of serious games in museum visits and exhibitions: A systematic mapping study," in Games and Virtual Worlds for Serious Applications (VS-Games), 2016 8th International Conference on, 2016. https://doi.org/10.1109/VSGAMES.2016.7590371

[19]D. Birchall, M. Henson, A. Burch, D. Evans, and K. Haley Goldmann, "Levelling up: Towards best practice in evaluating museum games," in Museums and the Web conference, 2012, pp. $11-14$.

[20] M. Mortara, C. E. Catalano, G. Fiucci, and M. Derntl, "Evaluating the Effectiveness of Serious Games for Cultural Awareness: The Icura User Study," in International Conference on Games and Learning Alliance, 2013, pp. 276-289.

[21] J. Froschauer, I. Seidel, M. Gärtner, H. Berger, and D. Merkl, "Design and evaluation of a serious game for immersive cultural training," in Virtual Systems and Multimedia (VSMM), 2010 16th International Conference on, 2010, pp. 253-260. https://doi.org/10.1109/VSMM.2010.5665978

[22] S. Chen, Z. Pan, M. Zhang, and H. Shen, "A case study of user immersion-based systematic design for serious heritage games," Multimed. Tools Appl., vol. 62, no. 3, pp. 633-658, 2013. https://doi.org/10.1007/s11042-011-0864-4

[23]D. Christopoulos, P. Mavridis, A. Andreadis, and J. N. Karigiannis, "Using Virtual Environments to Tell the Story: "The Battle of Thermopylae,"” in Games and Virtual Worlds for Serious Applications (VS-GAMES), 2011 Third International Conference on, 2011, pp. 8491. https://doi.org/10.1109/VS-GAMES.2011.18

[24] N. Lercari, M. Forte, L. Onsurez, and J. Schultz, "Multimodal reconstruction of landscape in serious games for heritage: An insight on the creation of Fort Ross Virtual Warehouse serious game," in Digital Heritage International Congress (DigitalHeritage), 2013, vol. 2, pp. 231-238. https://doi.org/10.1109/DigitalHeritage.2013.6744759

[25] J.-L. Shih, S.-C. Jheng, and J.-J. Tseng, "A simulated learning environment of history games for enhancing players' cultural awareness,” Interact. Learn. Environ., vol. 23, no. 2, pp. 191-211, 2015. https://doi.org/10.1080/10494820.2014.997249

[26] L. M. Castaneda, S. W. Bindman, A. Cechony, and M. Sidhu, "The Disconnect Between Real and Virtually Real Worlds: The Challenges of Using VR with Adolescents," Presence Teleoperators Virtual Environ., vol. 26, no. 4, pp. 453-464, 2018. https://doi.org/10.1162/PRES_a_00310 
[27] B. Dalgarno and M. J. W. Lee, "What are the learning affordances of 3-D virtual environments?" Br. J. Educ. Technol., vol. 41, no. 1, pp. 10-32, 2010. https://doi.org/10.1111/j.14678535.2009.01038.x

[28] I. Reisoğlu, B. Topu, R. Yılmaz, T. Karakuş Yılmaz, and Y. Göktaş, "3D virtual learning environments in education: a meta-review,” Asia Pacific Educ. Rev., vol. 18, no. 1, pp. 81-100, 2017. https://doi.org/10.1007/s12564-016-9467-0

[29] E. Christopoulou and S. Xinogalos, "Overview and Comparative Analysis of Game Engines for Desktop and Mobile Devices," Int. J. Serious Games, vol. 4, no. 4, pp. 21-36, 2017. https://doi.org/10.17083/ijsg.v4i4.194

[30]E. Champion, "The role of 3D models in virtual heritage infrastructures," in Cultural Heritage Infrastructures in Digital Humanities, Routledge, 2017, pp. 33-53.

[31]E. Champion, "Entertaining the similarities and distinctions between serious games and virtual heritage projects," Entertain. Comput., vol. 14, pp. 67-74, 2016. https://doi.org/10.1016/j.entcom.2015.11.003

[32] L. Kelly and A. Bowan, "Gamifying the museum: educational games for learning," in Museums and the Web Asia, 2014.

[33] Escape Hatch Entertainment, "Discover Babylon." Federation of American Scientists, available at: https://web.archive.org/web/20070516095349/http:/www.discoverbabylon.org:80/, 2007.

[34] M. Lucey-Roper, "Discover Babylon: Creating A Vivid User Experience by Exploiting Features of Video Games And Uniting Museum And Library Collections," in Museums and the Web, 2006.

[35] A. Crewdson, “Discover Babylon: E-Learning Power on Second Life," Sch. Libr. J., vol. 53, no. 11, pp. 38-39, 2007.

[36] J. Hall, "Indie Game Jam: An outlet for innovation and experimental game design," in Game Design Workshop: A Playcentric Approach to Creating Innovative Games, 2nd ed., Morgan Kaufmann, 2008, pp. 403-406.

[37] P. Turner, S. Turner, and L. Burrows, "Creating a Sense of Place with a Deliberately Constrained Virtual Environment," Int. J. Cogn. Perform. Support, vol. 1, no. 1, pp. 54-68, 2013. https://doi.org/10.1504/IJCPS.2013.053554

[38] M. Mortara and C. E. Catalano, “3D Virtual environments as effective learning contexts for cultural heritage,” Ital. J. Educ. Technol., vol. 26, no. 2, pp. 5-21, 2018.

[39]E. Champion, "Otherness of Place: Game-based Interaction and Learning in Virtual Heritage Projects,” Int. J. Herit. Stud., vol. 14, no. 3, pp. 210-228, 2008. https://doi.org/10.1080/13527250801953686

[40]L. Falconer and C. Scott, "Phenomenology and phenomenography in virtual worlds: An example from archaeology," in Virtual Worlds: Concepts, Applications and Future Directions, L. Falconer and M. C. Gil Ortega, Eds. New York, NY: Nova Science Publishers, 2018, pp. 138.

[41] J. A. A. Bakar, P. S. Jahnkassim, and M. Mahmud, "User Requirements for Virtual Reality in Architectural Heritage Leaning,” Int. J. Interact. Digit. Media, vol. 1, no. 1, pp. 37-45, 2013.

[42]H. Rahaman, "Digital heritage interpretation: a conceptual framework," Digit. Creat., vol. 29, no. 2-3, pp. 208-234, 2018. https://doi.org/10.1080/14626268.2018.1511602

[43] N. Ibrahim and N. M. Ali, "A Conceptual Framework for Designing Virtual Heritage Environment for Cultural Learning,” J. Comput. Cult. Herit., vol. 11, no. 2, p. 11.1-11.27, 2018.

[44] J. Urry, The Tourist Gaze, 2nd ed. London: Sage, 2002.

[45]P. Turner, S. Turner, and F. Carroll, "The Tourist Gaze: Towards Contextualised Virtual Environments," in Spaces, Spatiality and Technology, 1st ed., P. Turner and E. Davenport, Eds. Dordrecht: Springer Netherlands, 2005, pp. 281-297.

[46] S. Turner, C.-W. Huang, L. Burrows, and P. Turner, "Make-Believing Virtual Realities," in Digital Make-Believe, P. Turner and J. T. Harviainen, Eds. Cham: Springer International Publishing, 2016, pp. 27-47. https://doi.org/10.1007/978-3-319-29553-4_3

[47] P. Turner, "Presence: Is it just pretending?" AI Soc., vol. 31, no. 2, pp. 147-156, 2016. https://doi.org/10.1007/s00146-014-0579-y

[48] J. Steuer, "Defining virtual reality: dimensions determining telepresence," J. Commun., vol. 42, no. 4, pp. 73-93, 1992. https://doi.org/10.1111/j.1460-2466.1992.tb00812.x

[49]K. M. Lee, "Presence, Explicated," Commun. theory, vol. 14, no. 1, pp. 27-50, 2004. https://doi.org/10.1111/j.1468-2885.2004.tb00302.x

[50] M. Lombard and T. Ditton, “At the Heart of It All: The Concept of Presence," J. Comput. Commun., vol. 3, no. 2, 2006. 
[51] R. Skarbez, F. P. Brooks, Jr., and M. C. Whitton, "A Survey of Presence and Related Concepts," ACM Comput. Surv., vol. 50, no. 6, p. 96.1-96.39, 2018.

[52] J. Lessiter, J. Freeman, E. Keogh, and J. Davidoff, "A Cross-Media Presence Questionnaire: The ITC-Sense of Presence Inventory," Presence Teleoperators Virtual Environ., vol. 10, no. 3, pp. 282-297, 2001. https://doi.org/10.1162/105474601300343612

[53] M. Slater, M. Usoh, and A. Steed, "Depth of Presence in Virtual Environments," Presence Teleoperators Virtual Environ., vol. 3, no. 2, pp. 130-144, 1994. https://doi.org/10.1162/pres.1994.3.2.130

[54]J. van Baren and W. IJsselsteijn, "Measuring Presence: A Guide to Current Measurement Approaches," 2004.

[55]B. G. Witmer and M. J. Singer, "Measuring Presence in Virtual Environments: A Presence Questionnaire," Presence Teleoperators Virtual Environ., vol. 7, no. 3, pp. 225-240, 1998. https://doi.org/10.1162/105474698565686

[56] C. M. Bachen, P. Hernández-Ramos, C. Raphael, and A. Waldron, "How do presence, flow, and character identification affect players' empathy and interest in learning from a serious computer game?" Comput. Human Behav., vol. 64, pp. 77-87, 2016. https://doi.org/10.1016/j.chb.2016.06.043

[57] S. T. Bulu, "Place presence, social presence, co-presence, and satisfaction in virtual worlds," $\begin{array}{llllll}\text { Comput. } & \text { Educ., } & \text { vol. } 58, \quad \text { no. } 1, \quad \text { pp. }\end{array}$ https://doi.org/10.1016/j.compedu.2011.08.024

[58] S. Sylaiou, K. Mania, and I. Paliokas, "Exploring the effect of diverse technologies incorporated in virtual museums on visitors' perceived sense of presence," in Museums as intelligent environments workshop (MasIE), Proceedings of the 9th International Conference on Intelligent Environments, 2013, pp. 493-506.

[59] G. Gorisse, O. Christmann, E. A. Amato, and S. Richir, "First- and Third-Person Perspectives in Immersive Virtual Environments: Presence and Performance Analysis of Embodied Users," Front. Robot. AI, vol. 4, no. July, p. 33.1-33.12, 2017.

[60] M. P. McCreery, P. G. Schrader, S. K. Krach, and R. Boone, "A sense of self: The role of presence in virtual environments," Comput. Human Behav., vol. 29, no. 4, pp. 1635-1640, 2013. https://doi.org/10.1016/j.chb.2013.02.002

[61] E. Champion, "Cultural presence," in Encyclopedia of virtual communities and technologies, IGI Global, 2006, pp. 95-101. https://doi.org/10.4018/978-1-59140-563-4.ch018

[62] L. Pujol and E. Champion, "Evaluating presence in cultural heritage projects," Int. J. Herit. Stud., vol. 18, no. 1, pp. 83-102, 2012. https://doi.org/10.1080/13527258.2011.577796

[63] L. Pujol-Tost, "Cultural Presence in Virtual Archaeology: An Exploratory Analysis of Factors," Presence Teleoperators Virtual Environ., vol. 26, no. 3, pp. 247-263, 2018. https://doi.org/10.1162/pres_a_00296

[64] S. Harrison and P. Dourish, "Re-place-ing space: the roles of place and space in collaborative systems," in Proceedings of the 1996 ACM conference on Computer supported cooperative work, 1996, pp. 67-76. https://doi.org/10.1145/240080.240193

[65] V. Arora and D. Khazanchi, "Sense of Place in Virtual Learning Environments," in MWAIS 2014 Proceedings, 2014, p. Paper 8.

[66] P. Turner and S. Turner, "Place, Sense of Place, and Presence," Presence Teleoperators Virtual Environ., vol. 15, no. 2, pp. 204-217, 2006. https://doi.org/10.1162/pres.2006.15.2.204

[67] D. Benyon, M. Smyth, S. O’Neill, R. McCall, and F. Carroll, “The place probe: Exploring a sense of place in real and virtual environments," Presence Teleoperators Virtual Environ., vol. 15, no. 6, pp. 668-687, 2006. https://doi.org/10.1162/pres.15.6.668

[68] C. Zhang, A. Perkis, and S. Arndt, "Spatial Immersion versus Emotional Immersion, Which is More Immersive?" in Quality of Multimedia Experience (QoMEX), 2017 Ninth International Conference on, 2017. https://doi.org/10.1109/QoMEX.2017.7965655

[69] E. Brown and P. Cairns, "A grounded investigation of game immersion," in CHI '04 Extended Abstracts on Human Factors in Computing Systems, 2004, pp. 1297-1300.

[70]G. Calleja, In-game: From immersion to incorporation. MIT Press, 2011. https://doi.org/10.7551/mitpress/8429.001.0001

[71]L. Ermi and F. Mäyrä, "Fundamental Components of the Gameplay Experience: Analysing Immersion," in Worlds in Play: international perspectives on digital games research, 2007, pp. $37-55$.

[72] C. Jennett et al., "Measuring and defining the experience of immersion in games," Int. J. Hum. Comput. Stud., vol. 66, no. 9, pp. 641-661, 2008. https://doi.org/10.1016/j.ijhcs.2008.04.004 
pag. 116

[73] M. T. Cheng, H. C. She, and L. A. Annetta, "Game immersion experience: Its hierarchical structure and impact on game-based science learning," J. Comput. Assist. Learn., vol. 31, no. 3, pp. 232-253, 2015. https://doi.org/10.1111/jcal.12066

[74]P. Cairns, A. Cox, and A. I. Nordin, "Immersion in Digital Games: a Review of Gaming Experience Research," in Handbook of digital games, M. C. Angelides and H. Agius, Eds. Wiley-IEEE Press, 2013, pp. 339-361.

[75] A. Bousseau, M. Kaplan, J. Thollot, and F. X. Sillion, "Interactive watercolor rendering with temporal coherence and abstraction," in Proceedings of the 4th international symposium on nonphotorealistic animation and rendering, 2006, pp. 141-149. https://doi.org/10.1145/1124728.1124751

[76] S. Serafi and G. Serafi, "Sound Design to Enhance Presence in Photorealistic Virtual Reality," in Proceedings of ICAD 04-Tenth Meeting of the International Conference on Auditory Display, 2004.

[77] C. Hodent, "Design Thinking," in The Gamer's Brain: How Neuroscience and UX can Impact Video Game Design, CRC Press, 2018, pp. 173-184. 